Check for updates

Cite this: RSC Adv., 2017, 7, 36562

Received 12th June 2017

Accepted 18th July 2017

DOI: 10.1039/c7ra06553a

rsc.li/rsc-advances

\section{An electrochemical biosensor for detection of the sepsis-related biomarker procalcitonin $\uparrow$}

\author{
Jong Min Lim, ${ }^{a}$ Myung Yi Ryu, ${ }^{a} \mathrm{Ji} \mathrm{Hong} \mathrm{Kim}^{\text {a }}$ Chae Hwan Cho, ${ }^{\mathrm{a}}$ Tae Jung Park ${ }^{\mathrm{b}}$ \\ and Jong Pil Park (D) *a
}

An electrochemical peptide sensor employing a sensitive synthetic peptide was designed for the diagnosis of sepsis. A series of synthetic peptides were chemically synthesized, and the binding events and performance of the sensor were monitored by CV and EIS. PCT BP3, selected as a potential high-affinity peptide, was found to have a $K_{\mathrm{d}}$ value of $0.39 \pm 0.11 \mathrm{nM}$ for procalcitonin.
Sepsis is a serious systemic inflammatory response that can be caused by a bacterial, viral, or fungal infection, and is a primary cause of patient death in spite of medical advances, such as the new generation of antibiotics or other chemical therapies. ${ }^{1-4}$ One of the greatest limitations to the early diagnosis of sepsis is that its clinical symptoms-including fever, arterial hypotension, and thrombocytopenia-are highly variable, nonspecific, and heterogeneous because of the independent cellular metabolic responses that occur during sepsis progression. Such delay in diagnosis invariably leads to an increase in patient mortality. Under such circumstances, there is an increasing demand for the early detection of, and reliable diagnostic methods for, sepsis that could achieve improved results as well as the reduction of deaths and medical costs. To address these problems, several methods for sepsis diagnosis, including PCR, ${ }^{1}$ electrochemical immunoassay, ${ }^{5}$ and surface plasmon resonance, ${ }^{6}$ have been developed. There is also interest in the use of some blood biomarkers for the early detection of sepsis, including C-reactive protein (CRP), procalcitonin (ProCT), various cytokines, and cell surface markers. ${ }^{7,8}$ CRP has been used because of its high specificity. In comparison, ProCT is ubiquitously and uniformly expressed in multiple organ tissues. There are several benefits to the use of ProCT in disease diagnosis. First, the levels of ProCT are rapidly increased in normal serum within $12-48 \mathrm{~h}$ after bacterial invasion. ${ }^{9,10}$ Second, serum ProCT is more sensitive and specific than other serum biomarkers, including lactate, CRP, and IL-6. Thus, a ProCTbased immunoassay has recently been approved by the US FDA and is already commercially available. Therefore, elevated and circulating levels of ProCT have been widely studied as

\footnotetext{
aDepartment of Pharmaceutical Engineering, Daegu Haany University, Gyeongsan 38610, Republic of Korea. E-mail: jppark@dhu.ac.kr; Fax: +82-53-819-1406 ${ }^{b}$ Department of Chemistry, Chung-Ang University, Seoul 06974, Republic of Korea $\dagger$ Electronic supplementary information (ESI) available: Chemicals, preparation of electrode, CV and EIS measurements, information of synthetic peptides and additional results. See DOI: 10.1039/c7ra06553a
}

a promising biomarker for the early diagnosis of sepsis, , $^{311-13}$ even though it has limitations in differentiating sepsis from other inflammatory conditions.

Phage display is a powerful technique that allows for the isolation of high-affinity peptides that can bind to any target. Compared with the antibodies used in antibody-based immunoassays, unique peptides are more effective biorecognition elements for detecting various analytes. ${ }^{14-16}$ Some of the most exciting advantages of the peptides are their relatively small and their costeffectiveness for mass production and application in a biosensor platform. Importantly, small peptides can easily be integrated into miniaturized microsystems for point-of-care testing because they are relatively more stable than antibodies. As we had previously reported, the high-affinity peptides screened by M13 phage display have proven to be useful as alternative biorecognition elements that can bind to ProCT, ${ }^{17}$ norovirus-related proteins,${ }^{14}$ and colon cancer-related proteins, ${ }^{18}$ making them applicable for biosensor development.

The electrochemical detection method has been widely used for developing label-free and portable biosensors in many applications. ${ }^{16,19,20}$ According to previous studies, this promising technique is cost-effective, and has a fast response time and low maintenance. ${ }^{16}$ Therefore, cyclic voltammetry (CV) and electrochemical impedance spectroscopy (EIS) have been applied in the monitoring of analytes, being real-time, labelfree, and in situ techniques. ${ }^{21}$

Our group previously reported the use of biopanning with the M13 random peptide library to screen high-affinity peptides specific for the sepsis biomarker ProCT. ${ }^{17}$ From that study, we found phage-displayed peptide clones with a high sensitivity for ProCT, as confirmed by ELISA. Therefore, we posited that the free peptides from the phage-displayed particles could be used for the development of an electrochemical peptide sensor for the early diagnosis of sepsis. Based on the results from these screening and preliminary studies, we decided to test our hypothesis. To do this, a series of synthetic peptides were chemically synthesized (>95\% in purity), with a cysteine (Cys) 
residue at the $\mathrm{C}$-terminus to form a thiol self-assembled monolayer (SAM) and a flexible linker (-GGGGS-) for molecular flexibility. The binding events and the performance of the biosensor were then monitored by $\mathrm{CV}$ and EIS. The principle operation of our sensor system was shown in Fig. S1a, $\dagger$ and an equivalent circuit model of the system was also demonstrated in Fig. S1b. $\dagger$ The circuit consists of the solution resistance $\left(R_{\mathrm{s}}\right)$, the resistance of charge transfer $\left(R_{\mathrm{ct}}\right)$, double layer capacitance $\left(C_{\mathrm{dl}}\right)$ and Warburg impedance $(W) . R_{\mathrm{S}}$ and $W$ reflect the property of the solution, while $R_{\mathrm{ct}}$ in combination with $C_{\mathrm{dl}}$ depend on the electric property at the electrodeelectrolyte interface. In this study, a conventional three electrode cell including gold working electrode, platinum counter electrode, and $\mathrm{Ag} / \mathrm{AgCl}$ reference electrode was used for the electrochemical analysis. The characteristics of four synthetic peptides are shown in Table S1.† PCT BP1, which was identified through phage display, was used as the scaffold to progressively produce the other peptide analogs. PCT BP1 is rich in hydrophobic uncharged (e.g., Met, Ala, Phe, and Val) and basic (e.g., His and Arg) residues; its pI value was about 8.06. PCT BP2, which was made by substituting His with Asp at position 6 and Arg with Glu at position 10 in PCT $\mathrm{BP} 1$, was used to evaluate the effects of polar (positive) amino acid residues on the binding interactions; its pI value was 3.55. PCT BP3, which was made by substituting Met with Thr at positions 1 and 7, Ala with Asn at position 4, Phe Tyr at position 11, and Val with Asn at position 12 in PCT BP1, was used to investigate the effects of neutral amino acid residues on the binding interactions; its pI value was found to be 8.06. Lastly, PCT BP4, which was synthesized by substituting Cys with Gly at positions 3 and 8 , was used to evaluate the importance of Cys on the binding interactions; its pI value was predicted to be about 8.55. Based on previous sequencebased analytical results, we first wanted to select potential high-affinity peptides for the creation of an electrochemical sensor for ProCT detection. To select the best peptides capable of binding to ProCT, the four synthetic peptides (25 $\mu \mathrm{g} \mathrm{mL}^{-1}$ ) were respectively immobilized overnight on gold electrodes. Thereafter, after washing the electrode with distilled water, ProCT at the concentration of $25 \mu \mathrm{g} \mathrm{mL}{ }^{-1}$ was incubated on the pre-functionalized gold layer, and the decrease in current and the increase in impedance were monitored by CV and EIS, respectively. It was found that the four synthetic peptides had successfully attached to the gold surface layer with thiol-SAM and caused a decrease in current and an increase in impedance. Among the four synthetic peptides applied, PCT BP3 showed the most significant changes in current and impedance values. As clearly shown by both CV and EIS (Fig. 1 and 2), specific binding of ProCT with PCT BP3 had occurred on the gold surface layer. A dynamic and quantitative change was observed with PCT BP3 by $\mathrm{CV}$. This was in good agreement with the results obtained by EIS (Fig. 2). In general, an EIS spectrum is commonly represented by a Nyquist plot with $Z^{\prime}$ versus $Z^{\prime \prime}$, where $Z^{\prime}$ and $Z^{\prime \prime}$ are a real part and an imaginary part, respectively. The value of $R_{\mathrm{ct}}$ is approximately equal to the diameter of the semicircle. Therefore, a larger semicircle indicates a larger
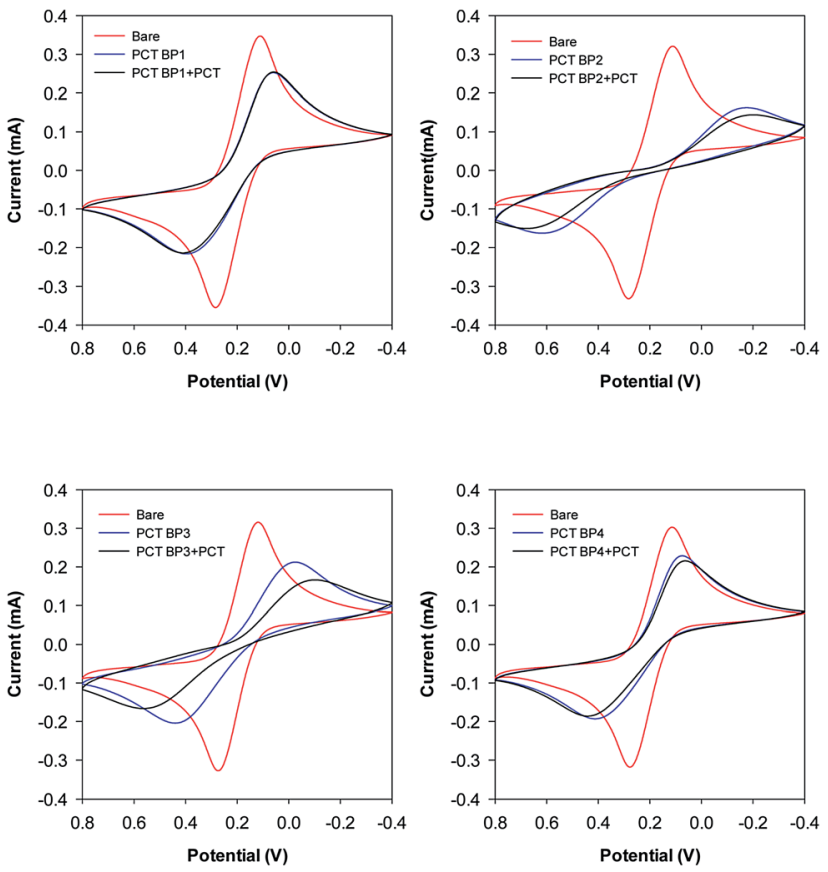

Fig. 1 Selection of synthetic peptides. A series of synthetic peptides were respectively immobilized onto a gold surface layer and the change of current was measured by cyclic voltammetry.

value for $R_{\mathrm{ct}}$. The relative $R_{\mathrm{ct}}$ signal changed according to the increased binding of ProCT to the synthetic peptides. $R_{\mathrm{ct}}$ could be calculated by the following equation (Grewal et al. 2014): ${ }^{22}$
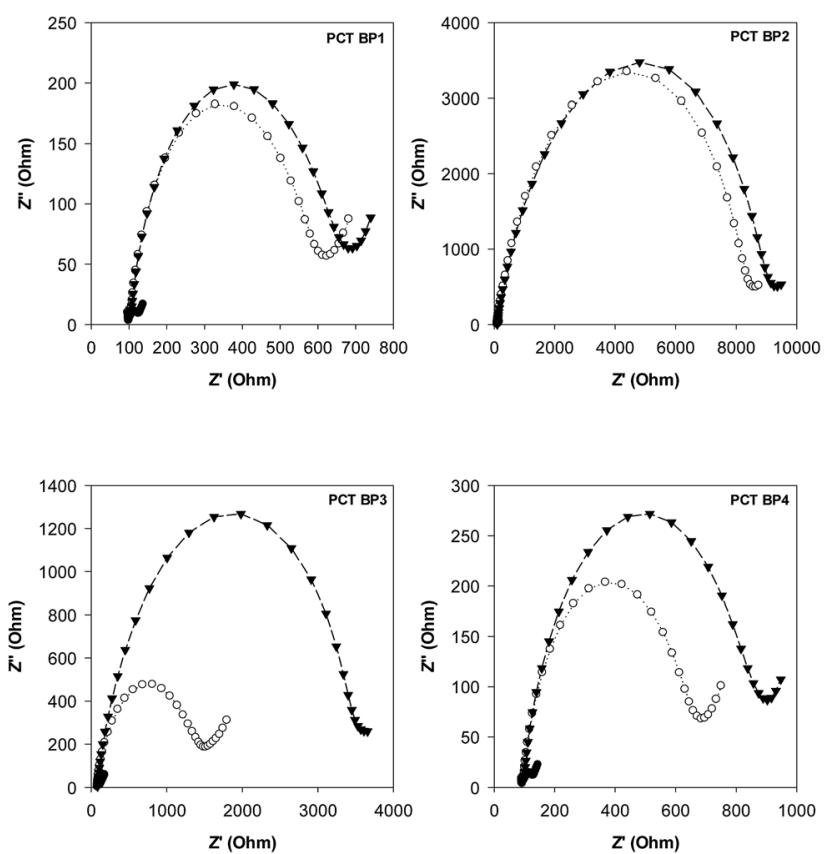

Fig. 2 Selection of synthetic peptides. A series of synthetic peptides were respectively immobilized onto a gold surface layer and the change of impedance was measured by electrochemical impedance spectroscopy ( $\bullet$, bare gold; $\bigcirc$, РCT immobilization; $\boldsymbol{\nabla}$, synthetic peptide addition). 


$$
\Delta R_{\mathrm{ct}}=\left(R_{\mathrm{ct}, \text { protein }}-R_{\mathrm{ct}, \text { peptide }}\right) / R_{\mathrm{ct}, \text { peptide }} \times 100
$$

where $R_{\text {ct,peptide }}$ is the mean value of $R_{\mathrm{ct}}$ after immobilization of the peptides only (no addition of target protein), and $R_{\mathrm{ct} \text {,protein }}$ the mean value of $\Delta R_{\mathrm{ct}}$ after addition of the target proteins. However, no significant changes were observed by CV and EIS when PCT BP1, BP2, and BP4 were applied, indicating that the binding affinity of these three peptides for ProCT was much lower than that of PCT BP3. From the immobilization and screening processes, we chose PCT BP3 as the potential highaffinity peptide for binding to ProCT. To further explore the optimal synthetic peptide and ProCT concentrations on the binding interactions, the concentration of PCT BP3 was varied

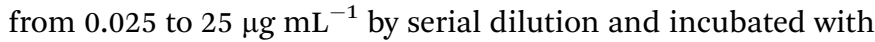
ProCT. The quantitative response using PCT BP3 peptides on the gold electrode was measured before and after incubation with ProCT. As shown in Fig. 3a, a dynamic change in impedance was observed, in a concentration-dependent manner. We also confirmed the effects of ProCT concentration on the
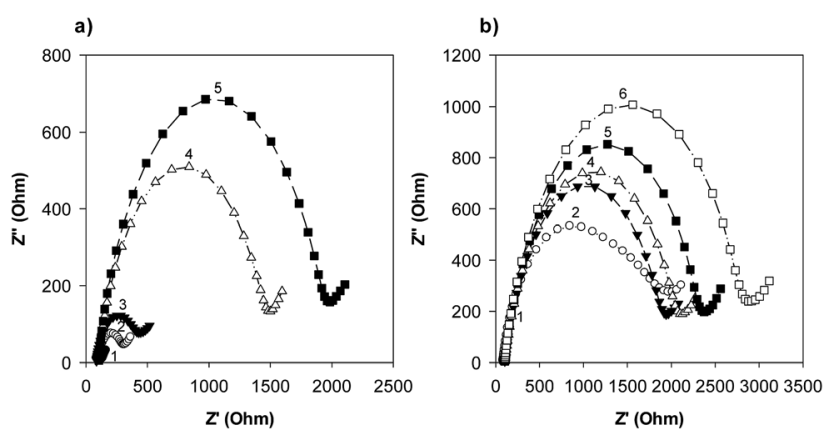

Fig. 3 Effects of different PCT BP3 (a) and ProCT (b) concentrations on the binding interactions. PCT BP3 peptides were varied from 0.025 to $25 \mu \mathrm{g} \mathrm{mL}^{-1}$ (1, bare; $2,0.025 \mu \mathrm{g} \mathrm{mL}^{-1} ; 3,0.25 \mu \mathrm{g} \mathrm{mL}^{-1} ; 4,2.5 \mu \mathrm{g}$ $\mathrm{mL}^{-1} ; 5,25 \mu \mathrm{g} \mathrm{mL}^{-1}$ ) and the change of impedance was monitored by electrochemical impedance spectroscopy. The concentrations of ProCT protein were also varied from 0.025 to $25 \mu \mathrm{g} \mathrm{mL}^{-1}$ (1, bare; 2 , $0.025 \mu \mathrm{g} \mathrm{mL}^{-1} ; 3,0.25 \mu \mathrm{g} \mathrm{mL}^{-1} ; 4,2.5 \mu \mathrm{g} \mathrm{mL}^{-1} ; 5,10 \mu \mathrm{g} \mathrm{mL}^{-1} ; 6,25 \mu \mathrm{g}$ $\mathrm{mL}^{-1}$ ) and the change of impedance was monitored by electrochemical impedance spectroscopy.

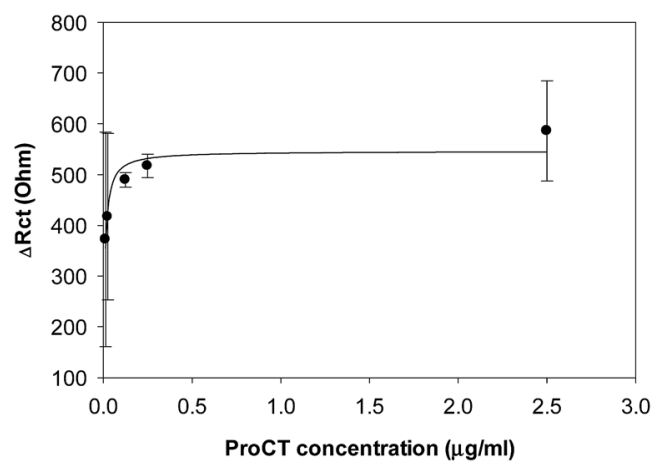

Fig. 4 Determination of the binding constant. ProCT, varying from 0 to $2.5 \mu \mathrm{g} \mathrm{mL}^{-1}$, was added to the pre-immobilized PCT BP3 peptides ( $25 \mu \mathrm{g} \mathrm{mL}^{-1}$ ) and the impedance change was measured by electrochemical impedance spectroscopy at $25^{\circ} \mathrm{C}$. binding events. PCT BP3 peptide $\left(25 \mu \mathrm{g} \mathrm{mL}^{-1}\right)$ was first immobilized onto the gold electrodes and ProCT ranging from 0.0025 to $25 \mu \mathrm{g} \mathrm{mL} \mathrm{m}^{-1}$ in concentration was applied, respectively. Thereafter, the impedance change was measured by EIS. As shown in Fig. 3b, a dynamic response was clearly observed. Fig. 4 shows the EIS measurements for determination of the binding constant $\left(K_{\mathrm{d}}\right)$ of PCT BP3 for ProCT, which was found to be $0.39 \pm 0.11 \mathrm{nM}$. The limit of detection (LOD) in EIS was 12.5 $\mathrm{ng} \mathrm{mL}^{-1}$ which is close to the normal level of ProCT in patients with sepsis derived from bacterial infection (0.1-0.5 $\mathrm{ng} \mathrm{mL} \mathrm{mL}^{-1}$ ) and septic shock (4-45 $\left.\mathrm{ng} \mathrm{mL}^{-1}\right) .{ }^{23}$ Importantly, a strong linearity between $R_{\mathrm{ct}}$ and ProCT concentration was seen in the range of $0.0125-0.25 \mu \mathrm{g} \mathrm{mL} \mathrm{m}^{-1}$. The stability of the sensor was stable within $5 \mathrm{~h}$ (Fig. S2a $\dagger$ ). We also investigated the effect of serum on binding interactions. Interestingly, binding affinity of PCT BP3 peptides was comparable in the presence of $0.5 \%$ FBS (Fig. S2b $\dagger$ ). Therefore, we concluded that the PCT BP3 synthetic peptides, as biorecognition elements, can be nanomolar binders for ProCT and thus useful for the monitoring of sepsis progression.

\section{Conclusions}

We had previously found that a novel peptide (MSCAGHMCTRFV) defined through phage display, was quite specific for the sepsis biomarker ProCT according to ELISA measurements. We therefore evaluated whether the free peptides from the phage particles could be used to develop an electrochemical peptide sensor for the early diagnosis of sepsis. Among the tested synthetic peptides, we observed that PCT BP3 had the highest binding affinity for ProCT. Our newly created sensor based on the PCT BP3 peptide coupled with EIS detection had a $K_{\mathrm{d}}$ of $0.39 \pm 0.11 \mathrm{nM}$ for ProCT. Although this approach will require further evaluation for clinical use, the combination of a high-affinity peptide and electrochemical detection has some benefits compared with other bioanalytical methods. Most affinity peptides are their small size and costeffective for manipulation and mass production. They are also amenable than antibodies to engineering at molecular scale. Thus, the performance of our sensor system on real patient samples and in the presence of other sample matrixes is currently under investigation to investigate the applicability (specificity and reliability) of the sensor.

\section{Acknowledgements}

This study was supported by National Research Foundation of Korea (NRF) grants funded by the Korea government (MSIP) (NRF2014R1A2A2A01005621 and NRF-2017R1A2A2A05001037). Additional support was provided by a part of the project titled "Development of portable impedance detection system for food poisoning virus in sea foods" from the Ministry of Oceans and Fisheries, Republic of Korea (20160122).

\section{Notes and references}

1 M. Kemmler, U. Sauer, E. Schleicher, C. Preininger and A. Brandenburg, Sens. Actuators, B, 2014, 192, 205-215. 
2 J. Cohen, C. Brun-Buisson, A. Torres and J. Jorgensen, Crit. Care Med., 2004, 32, S466-S494.

3 T. Rowland, H. Hilliard, G. Barlow and S. M. Gregory, in Advances in Clinical Chemistry, Elsevier, 2015, vol. 68, pp. 71-86.

4 D. Anand, S. Das, S. Bhargava, L. M. Srivastava, A. Garg, N. Tyagi, S. Taneja and S. Ray, J. Crit. Care, 2015, 30, 218.

5 H. Li, Y. Sun, J. Elseviers, S. Muyldermans, S. Liu and Y. Wan, Analyst, 2014, 139, 3718-3721.

6 G. Sener, E. Ozgur, A. Y. Rad, L. Uzun, R. Say and A. Denizli, Analyst, 2013, 138, 6422-6428.

7 P. M. Kramer, M. Kess, E. Kremmer and S. Schulte-Hostede, Analyst, 2011, 136, 692-695.

8 S. Kibe, K. Adams and G. Barlow, J. Antimicrob. Chemother., 2011, 66, ii33-ii40.

9 B. M. Tang, G. D. Eslick, J. C. Craig and A. S. McLean, Lancet Infect. Dis., 2007, 7, 210-217.

10 A. A. Dahaba, B. Hagara, A. Fall, P. H. Rehak, W. F. List and H. Metzler, Br. J. Anaesth., 2006, 97, 503-508.

11 A. Viallon, F. Zeni, C. Lambert, B. Pozzetto, B. Tardy, C. Venet and J.-C. Bertrand, Clin. Infect. Dis., 1999, 28, 1310-1316.

12 L. Simon, F. Gauvin, D. K. Amre, P. Saint-Louis and J. Lacroix, Clin. Infect. Dis., 2004, 39, 206-217.
13 Y. Nakamura, A. Murai, M. Mizunuma, D. Ohta, Y. Kawano, N. Matsumoto, T. Nishida and H. Ishikura, J. Infect. Chemother., 2015, 21, 257-263.

14 H. J. Hwang, M. Y. Ryu and J. P. Park, RSC Adv., 2015, 68, 55300-55302.

15 J. W. Kehoe and B. K. Kay, Chem. Rev., 2005, 105, 4056-4072.

16 J. Wu, J. P. Park, K. Dooley, D. M. Cropek, A. C. West and S. Banta, PLoS One, 2011, 6, e24948.

17 J. P. Park, C. Y. Park, A. Y. Park and M. Y. Ryu, RSC Adv., 2015, 5, 90531-90533.

18 H. J. Hwang, M. Y. Ryu, G. B. Lee and J. P. Park, ChemistrySelect, 2016, 1, 1140-1143.

19 H. J. Hwang, M. Y. Ryu, C. Y. Park, J. Ahn, H. G. Park, C. Choi, S.-D. Ha, T. J. Park and J. P. Park, Biosens. Bioelectron., 2017, 87, 164-170.

20 R. Hu, W. Wen, Q. Wang, H. Xiong, X. Zhang, H. Gu and S. Wang, Biosens. Bioelectron., 2014, 53, 384-389.

21 N. Wang, K. Burugapalli, W. Song, J. Halls, F. Moussy, A. Ray and Y. Zheng, Biomaterials, 2013, 34, 888-901.

22 Y. S. Grewal, M. J. A. Shiddiky, L. J. Spadafora, G. A. Cangelosi and M. Trau, Br. J. Anaesth., 2014, 55, 417422.

23 F. Bloos and K. Reinhart, Virulence, 2014, 5, 154-160. 